\title{
Aproximaciones conceptuales al principio de progresividad y no regresividad de los derechos constitucionales*
}

\section{Conceptual approximation to the principal of progressivity and nonregressivity of constitutional rights}

\section{RESUMEN}

La Constitución Política de 1991 establece la figura de Estado constitucional, social, democrático y ambiental de Derecho, concepción que amplía el catálogo de derechos fundamentales, sociales, económicos, culturales y colectivos. El Derecho Internacional de los Derechos Humanos, la jurisprudencia constitucional y la doctrina se han referido al significado y alcance del principio de progresividad y no regresividad de los derechos constitucionales. Este escrito recoge una serie de reflexiones orientadas a establecer el papel del referido principio en la materialización de los cometidos estatales.

\section{PALABRAS CLAVE}

Estado Social de Derecho, Catálogo de Derechos, Derecho Internacional de los Derechos Humanos, Principio de progresividad.

\section{ABSTRACT}

The Political Constitution of 1991 establish the constitutional State figure, democratic and environmental law, a design that extends the catalog of fundamentals rights, social, economic, cultural and collective. The International Law of Human Rights, the case law and constitutional doctrine, has been referred to the meaning and scope of the principal of progressivity and nonregressivity of the constitutional rights. This writing contains a series of reflexions designed to establish the role of materialization of government commitment.

\section{KEYWORDS}

Social State Law, Catalog Rights, International Law of Human Rights, Principal of progressivity.

\section{NÉSTOR JAVIER CALVO}

Abogado y Especialista en Derecho Administrativo y Constitucional de la Universidad Libre Seccional Pereira. Magíster en Derecho de la Universidad de Manizales. Juez 1 Administrativo Oral de Cartago - Valle del Cauca. Docente de la Facultad de Derecho de la Universidad Libre Seccional Pereira. nestorjaviercalvo@yahoo.com

* El artículo es un resultado parcial de la investigación titulada El Principio de Progresividad y no Regresividad de los Derechos Constitucionales en el Estado Social de Derecho, desarrollada como requisito para optar al título de Doctor en Derecho de la Universidad Libre Seccional Bogotá. 
INTRODUCCIÓN

La Constitución Política de 1991 introdujo un cambio en la concepción de Estado colombiano, al establecer la figura de Estado constitucional, social, democrático y ambiental de Derecho, como evolución histórica y política del anterior Estado de Derecho.

De la misma manera, como parte de esa nueva concepción de Estado, se amplía el catálogo de derechos fundamentales, sociales, económicos, culturales y colectivos en cabeza de las personas, y se consagran diferentes mecanismos jurídicos para lograr su protección. Lo anterior establece mayores responsabilidades para las autoridades, quienes en el ejercicio de sus funciones deben superar las dificultades que plantea el cometido de realización paulatina de los derechos consagrados en la Constitución Política.

Por otra parte, se fortalece el papel de los jueces en la interpretación del Derecho, quienes a través del conocimiento de diversos asuntos les corresponde decidir sobre la protección efectiva de los derechos constitucionales en los casos particulares y concretos y el control de la actuación de las demás autoridades públicas. Ese nuevo rol dinámico de la función judicial ha representado en los últimos años múltiples conflictos con las diferentes autoridades del Estado, por cuanto se considera que algunas de las decisiones adoptadas por los jueces y tribunales invaden el ámbito de competencia de aquellas, desbordando el poder conferido en la Constitución Política y comprometiendo la estabilidad y la viabilidad del mismo Estado. A raíz de diferentes decisiones judiciales que se han referido a la ampliación progresiva de los derechos consagrados en la Constitución Política, se ha levantado polémica frente a la administración pública, la que argumentando la insuficiencia presupuestal, ha colocado en entredicho la conveniencia de dichos fallos, llegando hasta la promoción de reformas normativas que limiten las obligaciones del Estado frente a los particulares, determinando un retroceso en lo consagrado constitucionalmente.

\section{METODOLOGÍA}

La investigación que se desarrolló fue de tipo descriptivo, puesto que lo que se buscó fue establecer el significado y alcance del principio de progresividad y no regresividad de los derechos constitucionales. Para el efecto, a partir del Derecho Internacional de los Derechos Humanos, la jurisprudencia constitucional y la doctrina, se estableció cuál es el papel del principio de progresividad y no regresividad de los derechos constitucionales en un Estado constitucional, social, democrático y ambiental de Derecho.

Se acudió a un método de investigación de análisis, donde a partir de la teoría jurídica y la jurisprudencia se determina el papel de los principios en el Derecho, el significado del principio de progresividad y no regresividad de los derechos constitucionales, y finalmente el papel del principio de progresividad en la materialización de los cometidos estatales. 


\section{RESULTADOS PARCIALES}

Como tarea previa se hará la diferenciación en primer lugar entre reglas y principios, y en segundo lugar entre principios y valores constitucionales, para luego definir el concepto de principio de progresividad y no regresividad de los derechos constitucionales.

1. Reglas y principios. Atienza y Ruiz Manero (1991, p. 107) refieren que las normas pueden ser reglas o principios. Con respecto a la cuestión de cómo distinguir los principios de las reglas, los referidos autores explican lo siguiente (p. 108):

"En nuestra opinión, los principios en sentido estricto pueden formularse siempre como enunciados que correlacionan casos con soluciones, pero eso no quiere decir que, desde esta perspectiva, no exista ninguna diferencia entre reglas y principios. La diferencia estriba en que los principios configuran el caso de forma abierta, mientras que las reglas lo hacen de forma cerrada. Con ello queremos decir que mientras que en las reglas las propiedades que conforman el caso constituyen un conjunto cerrado, en los principios no puede formularse una lista cerrada de las mismas: no se trata solo de que las propiedades que constituyen las condiciones de aplicación tengan una periferia mayor o menor de vaguedad, sino de que tales condiciones no se encuentran siquiera genéricamente determinadas. El tipo de indeterminación que aqueja a los principios es, pues, más radical que el de las reglas (aunque, desde luego, entre uno y otro tipo de indeterminación puede haber casos de penumbra).

Robert Alexy, desarrollando, por lo demás, algo que ya estaba presente en Dworkin, ha escrito que 'el punto decisivo para la distinción entre reglas y principios es que los principios son normas que ordenan que se realice algo en la mayor medida posible, en relación con las posibilidades jurídicas y fácticas. Los principios son, por consiguiente, mandatos de optimización que se caracterizan porque pueden ser cumplidos en diversos grados y porque la medida ordenada de su cumplimiento no solo depende de las posibilidades fácticas sino también de las posibilidades jurídicas. El campo de las posibilidades jurídicas está determinado a través de principios y reglas que juegan en sentido contrario. En cambio, las reglas son normas que exigen un cumplimiento pleno $y$, en esta medida, pueden siempre ser solo cumplidas o incumplidas. Si una regla es válida entonces hacer precisamente lo que ordena, ni más ni menos'" (Alexy, 1993, pp. 143-4).

\section{Principios y valores constitucionales. La} Corte Constitucional en Sentencia T-406 del 5 de junio de 1992 destaca el nuevo papel que juegan los principios constitucionales en las decisiones judiciales y su relación con los valores y normas de la Carta. 
Para el efecto explica que "los valores representan el catálogo axiológico a partir del cual se deriva el sentido y la finalidad de las demás normas del ordenamiento jurídico pueden tener consagración explícita o no; lo importante es que sobre ellos se construya el fundamento y la finalidad de la organización política". Siendo de este tipo los plasmados en el preámbulo de la Constitución y los consagrados en el inciso primero del artículo 2 de la Constitución en referencia a los fines del Estado.

Con respecto a los principios constitucionales, la misma Corporación establece que " $a$ diferencia de los valores que establecen fines, consagran prescripciones jurídicas generales que suponen una delimitación política y axiológica reconocida y, en consecuencia, restringen el espacio de interpretación, lo cual hace de ellos normas de aplicación inmediata, tanto por el legislador como por el juez constitucional". Siendo principios constitucionales, los consagrados en los artículos primero y tercero, que hacen referencia a la naturaleza política y organizativa del Estado y de las relaciones entre los gobernantes y los gobernados. Dichos principios son una pauta de interpretación por ser parte de la Constitución misma y están dotados de la fuerza normativa que les otorga el artículo cuarto del texto fundamental.

\section{Principio de progresividad y no regresivi-} dad de los derechos constitucionales. Ahora se indicará cuál es el significado que ha atribuido el Derecho Internacional de los Derechos Humanos, la jurisprudencia constitucio- nal y la doctrina a dicho principio; qué otros significados jurídicos tiene el principio de progresividad y cuál es el papel del principio de progresividad y no regresividad de los derechos constitucionales en un Estado constitucional, social, democrático y ambiental de Derecho.

Significado a partir del Derecho Internacional de los Derechos Humanos. El principio de progresividad tiene sustento en el Derecho Internacional de los Derechos Humanos, ya que este contempla la obligación de los Estados Partes de lograr el desarrollo progresivo de los derechos económicos, sociales y culturales.

El artículo 2.1. del Pacto Internacional de Derechos Económicos, Sociales y Culturales -PIDESC- de 16 de diciembre de 1966, establece:

"1. Cada uno de los Estados Partes en el presente Pacto se compromete a adoptar medidas, tanto por separado como mediante la asistencia y la cooperación internacionales, especialmente económicas y técnicas, hasta el máximo de los recursos de que disponga, para lograr progresivamente, por todos los medios apropiados, inclusive en particular la adopción de medidas legislativas, la plena efectividad de los derechos aquí reconocidos".

De conformidad con la Observación General No. 3 del Comité del Pacto de Derechos Económicos, Sociales y Culturales, "La índole de 
las obligaciones de los Estados Partes (párrafo 1 del artículo 2 del Pacto)" adoptada en el Quinto Período de Sesiones de 1990, documento E/1991/23, las obligaciones contraídas por los Estados Partes del Pacto Internacional DESC (PIDESC) se dividen en obligaciones de comportamiento y en obligaciones de resultado. En las últimas se incluye la obligación de adoptar medidas para la progresiva satisfacción de los derechos contemplados en el Pacto, es decir, el mandato de progresividad y la prohibición de medidas regresivas en materia de los DESC. Dicho Comité precisó el alcance del artículo 2.1. del PIDESC en los siguientes términos:

"La principal obligación en lo que atañe a resultados que se refleja en el párrafo 1 del artículo 2 es la de adoptar medidas "para lograr progresivamente... la plena efectividad de los derechos reconocidos [en el Pacto]". La expresión "progresiva efectividad" se usa con frecuencia para describir la intención de esta frase. El concepto de progresiva efectividad constituye un reconocimiento del hecho de que la plena efectividad de todos los derechos económicos, sociales y culturales en general no podrá lograrse en un breve período de tiempo. En este sentido, la obligación difiere de manera importante de la que figura en el artículo 2 del Pacto Internacional de Derechos Civiles y Políticos e incorpora una obligación inmediata de respetar y garantizar todos los derechos pertinentes. Sin embargo, el hecho de que la efectividad a lo largo del tiempo, o en otras palabras progresivamente, se prevea en relación con el Pacto no se ha de interpretar equivocadamente como que priva a la obligación de todo contenido significativo. Por una parte, se requiere un dispositivo de flexibilidad necesaria que refleje las realidades del mundo real y las dificultades que implica para cada país el asegurar la plena efectividad de los derechos económicos, sociales y culturales. Por otra parte, la frase debe interpretarse a la luz del objetivo general, en realidad la razón de ser, del Pacto, que es establecer claras obligaciones para los Estados Partes con respecto a la plena efectividad de los derechos de que se trata. Este impone así una obligación de proceder lo más expedita y eficazmente posible con miras a lograr ese objetivo. Además, todas las medidas de carácter deliberadamente retroactivo en este aspecto requerirán la consideración más cuidadosa y deberán justificarse plenamente por referencia a la totalidad de los derechos previstos en el Pacto y en el contexto del aprovechamiento pleno del máximo de los recursos de que se disponga".

Con respecto al anterior fundamento de Derecho Internacional, la Corte Constitucional, (Sentencia C-443 de 2009. Referencia: expediente D-7419. Demanda de inconstitucionalidad contra el artículo 34 (parcial) de la Ley 685 de 2001 "por la cual se expide el Código de Minas". Actores: Daniel Manrique y Je- 
rónimo Rodríguez Lugo. M. P. Dr. Humberto Antonio Sierra Porto. Bogotá, D. C., ocho (8) de julio de dos mil nueve (2009) ha señalado que "el mandato de progresividad, que se desprende del artículo $2.1 \mathrm{del}$ PIDESC, tiene dos contenidos complementarios (Courtis, 2008, pp. 8 y ss), por un lado el reconocimiento de que la satisfacción plena de los derechos establecidos en el pacto supone una cierta gradualidad. Por otra parte, también implica un segundo sentido, el de progreso, consistente en la obligación estatal de mejorar las condiciones de goce y ejercicio de los derechos económicos, sociales y culturales. Así el Comité de Derechos Económicos, Sociales y Culturales ha expresado que 'el concepto de realización progresiva constituye un reconocimiento del hecho de que la plena realización de los derechos económicos, sociales y culturales, generalmente no podrán lograrse en un corto período de tiempo'”**.

A su vez el artículo 11.1. del PIDESC establece que "los Estados Partes en el presente Pacto reconocen el derecho de toda persona a un nivel de vida adecuado para sí y su familia, incluso alimentación, vestido y vivienda adecuados, y a una mejora continua de las condiciones de existencia...".

Courtis (2006, p. 9) señala que el anterior artículo resume en gran medida el significado de los derechos sociales en cuanto a la garantía de un nivel de vida adecuado y la identificación de los componentes mínimos a te- ner en consideración para dar sentido a esa noción de adecuación. "Adicionalmente, el Pacto requiere la mejora continua de las condiciones de existencia, es decir, la progresividad en el sentido de progreso, o ampliación de la cobertura y protección de los derechos sociales".

Las Observaciones Generales 14 (párr. 4), 15 (párr. 42) y 17 (párr. 42) establecen una prohibición absoluta de regresividad cuando la medida afecte la satisfacción de niveles esenciales de los derechos a la salud y al agua.

También ha señalado la jurisprudencia constitucional (Corte Constitucional. C-228 de 2011. Referencia: expediente D-8216. Demanda de inconstitucionalidad parcial del artículo $6^{\circ}$ del Decreto-Ley 1282 de 1994 y parcial de los artículos 9 y 10 de la Ley 797 de 2003) ${ }^{\circ}$ con respecto al principio de progresividad de los derechos económicos, sociales y culturales:

"Por otra parte se ha venido introduciendo dicho principio a través de la recepción de los criterios dados por los Principios de Limburgo de 1987 y las Directrices de Maastricht de 1997, que son recomendaciones de implementación y comprensión de los derechos consagrados en el PIDESC elaboradas por expertos en el campo del

\footnotetext{
- Actores: María Fernanda Orozco Tous y Nixon Torres Cárcamo. M. P. Juan Carlos Henao Pérez. Bogotá, D.C., treinta (30) de marzo de dos mil once (2011).
} 
Derecho Internacional y que se han convertido en una fuente directa para comprender la forma de aplicación e interpretación de estos derechos. Por ejemplo en la Directriz No. 9 de Maastricht se estableció que el principio de progresividad de los derechos económicos, sociales y culturales, estipulado en el artículo 2 del PIDESC, no debe ser utilizado como pretexto para su incumplimiento, y que se debe garantizar los niveles mínimos esenciales de cada uno de los derechos si no se cuenta con todos los recursos para atender a estos derechos"*.

Los Principios de Limburgo relativos a la Aplicación del PIDESC fueron elaborados por un grupo de expertos reunidos entre el 2 y el 6 de junio de 1986 en la ciudad holandesa de Maastricht y adoptados por Naciones Unidas (Courtis, 2006, p. 13).

Las Directrices de Maastricht sobre Violaciones a los Derechos Económicos, Sociales y Culturales, adoptadas por un grupo de expertos entre el 22 y el 26 de enero de 1997 en la ciudad holandesa de Maastricht, son un instrumento de interpretación utilizado por

* Esta misma idea se da en la Observación General No. 3 del Comité de Derechos Económicos, Sociales y Culturales de Naciones Unidas que estableció que, "El concepto de realización progresiva constituye un reconocimiento del hecho de que la plena realización de los derechos económicos, sociales y culturales generalmente no podrá lograrse en un período corto de tiempo. Sin embargo, el hecho de que el Pacto prevea que la realización requiere un cierto tiempo, en otras palabras sea progresiva, no debe ser malinterpretado en el sentido de privar a la obligación de todo contenido significativo...". los órganos de supervisión de tratados internacionales en materia de derechos económicos, sociales y culturales. Según dicho documento son violaciones de dichos derechos, la derogación o suspensión de la legislación necesaria para el goce continuo de uno de esos derechos; la adopción de legislación o de políticas manifiestamente incompatibles con obligaciones legales preexistentes relativas a esos derechos, salvo que su propósito y efecto sean el de aumentar la igualdad y mejorar la realización del mismo tipo de derechos; y la adopción de cualquier medida deliberadamente regresiva que reduzca el alcance en el que se garantiza el derecho (p. 11).

El artículo 26 de la Convención Americana de Derechos Humanos, "Pacto de San José de Costa Rica"•, suscrita en la Conferencia especializada interamericana sobre derechos humanos en San José, Costa Rica, el 22 de noviembre de 1969, señala:

\section{CAPÍTULO III}

DERECHOS ECONÓMICOS, SOCIALES Y CULTURALES

Artículo 26. Desarrollo Progresivo

Los Estados Partes se comprometen a adoptar providencias, tanto a nivel interno como mediante la cooperación internacional, especialmente econó-

- Con depósito de ratificación de Colombia del 31 de julio de 1973. 
mica y técnica, para lograr progresivamente la plena efectividad de los derechos que se derivan de las normas económicas, sociales y sobre educación, ciencia y cultura, contenidas en la Carta de la Organización de los Estados Americanos, reformada por el Protocolo de Buenos Aires, en la medida de los recursos disponibles, por vía legislativa u otros medios apropiados.

Courtis (2006, pp. 13-14) afirma que en cuanto a la remisión de la Carta de la OEA, "son al menos identificables en forma clara los siguientes derechos: el derecho a la educación; los derechos laborales; el derecho a la seguridad social; el derecho a la vivienda; el derecho a la alimentación; el derecho a la salud y los derechos culturales". Pero considera que "la prohibición de regresividad también constituye, en principio, una obligación general de la Convención Americana sobre Derechos Humanos, y es aplicable por ende a todos los derechos establecidos por la Convención".

Con respecto a la mención de "en la medida de los recursos disponibles", es calificada por Courtis (2006, p. 50) como cláusula de condicionamiento económico, la que requiere el análisis de aspectos vinculados con la implementación de políticas públicas y la disposición de recursos.

A su turno, el artículo 1.1. del Protocolo Adicional a la Convención Americana sobre Derechos Humanos en materia de Derechos Económicos, Sociales y Culturales -Protocolo de San Salvador-", suscrito en San Salvador El Salvador, el 17 de noviembre de 1988, en el decimoctavo período ordinario de sesiones de la Asamblea General de la Organización de Estados Americanos -OEA-, consagra:

"Los Estados Partes en el presente Protocolo Adicional a la Convención Americana sobre Derechos Humanos se comprometen a adoptar las medidas necesarias tanto de orden interno como mediante la cooperación entre los Estados, especialmente económica y técnica, hasta el máximo de los recursos disponibles y tomando en cuenta su grado de desarrollo, a fin de lograr progresivamente, y de conformidad con la legislación interna, la plena efectividad de los derechos que se reconocen en el presente Protocolo".

Igualmente, el artículo 40 del anterior Protocolo establece que "no podrá restringirse o menoscabarse ninguno de los derechos reconocidos o vigentes en un Estado en virtud de su legis/ación interna o de convenciones internacionales, so pretexto de que el presente Protocolo no los reconoce o los reconoce en menor grado".

La Comisión Interamericana de Derechos Humanos de la OEA en el Capítulo V del Informe Anual 1993 se refiere a los campos en los cuales han de tomarse medidas para dar

* Con depósito de ratificación de Colombia del 23 de diciembre de 1997. 
mayor vigencia a los derechos humanos, de conformidad con la Declaración Americana de los Derechos y Deberes del Hombre y la Convención Americana sobre Derechos Humanos. Con respecto a la realización de los derechos económicos, sociales y culturales en la región, el documento en cita indica que el principio de desarrollo progresivo "no significa que los gobiernos no tengan la obligación inmediata de empeñarse por lograr la realización plena de tales derechos. El fundamento del principio de la realización progresiva de los derechos es que los gobiernos tienen la obligación de asegurar condiciones que, de acuerdo con los recursos materiales del Estado, permitan avanzar gradual y constantemente hacia la más plena realización de tales derechos".

A su vez el artículo 5.1. de las "Normas para la confección de los informes periódicos previstos en el artículo 19 del Protocolo de San Salvador", aprobadas por la Asamblea General de la Organización de los Estados Americanos el 7 de junio de 2005, consagra que para "los fines de este documento, por el principio de progresividad se entenderá el criterio de avance paulatino en el establecimiento de las condiciones necesarias para el ejercicio de un derecho económico, social y cultural".

Es de advertir que en los términos consagrados por el artículo 93 de la Constitución Política de Colombia de 1991, "los tratados y convenios internacionales ratificados por el Congreso, que reconocen los derechos humanos y que prohíben su limitación en los es- tados de excepción, prevalecen en el orden interno".

Significado a partir de la jurisprudencia constitucional colombiana. Por otro lado, de la Sentencia C-038 del 27 de enero de 2004 proferida por la Corte Constitucional se puede señalar que el mandato de progresividad en materia de derechos sociales ( 1 ) implica que el Estado tiene la obligación de iniciar inmediatamente el proceso encaminado a la completa realización de esos derechos, (II) hace referencia al reconocimiento de prestaciones y protecciones mayores y superiores en relación con cada uno de esos derechos sociales, (III) no excusa el incumplimiento del deber del Estado de asegurar, tan pronto como sea posible, los contenidos mínimos de esos derechos, e (IV) implica que una vez alcanzado un determinado nivel de protección, la amplia libertad de configuración del legislador en materia de derechos sociales se ve restringida.

El principio de progresividad se constituye en referente para la realización del Estado Social de Derecho consagrado en la Constitución Política de Colombia de 1991, teniendo sustento en el Derecho Internacional de los Derechos Humanos. La jurisprudencia constitucional (Corte Constitucional. Sentencia C-272 de 2009. Referencia: expediente D-7670. Accionante: Hernán Antonio Barrero Bravo. Demanda de inconstitucionalidad contra el artículo 1 (parcial) de la Ley 860 de 2003) (M.P. Dra. María Victoria Calle Correa. Bogotá, D.C., catorce (14) de octubre de dos mil nueve (2009), ha señalado que al ser Colom- 
bia un Estado Social de Derecho implica que "las autoridades están obligadas a corregir las visibles desigualdades sociales, a facilitar la inclusión y participación de sectores más marginados y vulnerables de la población en la vida económica y social de la Nación, y a estimular un mejoramiento progresivo de las condiciones materiales de existencia de los sectores más deprimidos de la sociedad". Dicho mandato se fundamenta en los artículos 1 (principio de la dignidad humana y de la solidaridad), 2 (fines esenciales del Estado), 13 (promoción de condiciones de igualdad real y efectiva), 334 (acceso efectivo a los bienes y servicios básicos por las personas de menores ingresos) y 366 (prioridad del gasto social en los planes y presupuestos de la Nación y de las entidades territoriales) de la Constitución Política.

De lo anterior, la misma jurisprudencia deriva dos clases de deberes para el Estado, el primero de adopción y puesta en marcha de medidas positivas para lograr una igualdad real de condiciones y oportunidades entre los asociados y al hacerlo, dar cumplimiento a sus obligaciones constitucionales de satisfacción progresiva de los derechos económicos, sociales y culturales básicos de la población (cláusula de erradicación de las injusticias presentes); y el segundo de abstención de adelantar, promover o ejecutar políticas, programas o medidas ostensiblemente regresivas en materia de derechos económicos, sociales y culturales, que conduzcan clara y directamente a agravar la situación de injusticia, de exclusión o de marginación que se pretende corregir, sin que ello impida avanzar gradual y progresivamente hacia el pleno goce de tales derechos.

El principio de progresividad ha sido aplicado por la jurisprudencia colombiana, como parámetro de control de constitucionalidad en abstracto y en concreto, en la efectividad de los derechos al trabajo, a la salud, a la seguridad social en pensiones, a la educación, al acceso a la propiedad, a la vivienda, al goce del medioambiente, de las personas con discapacidad y de los desplazados, y a la reparación integral a cargo del Estado en casos de responsabilidad extracontractual; así como también en la previsión de garantías judiciales para la exigibilidad de los derechos (Calvo, 2011, pp. 63-81).

Significado a partir de la doctrina. Courtis (2006, pp. 3-4) explica que existen dos nociones posibles de regresividad. La primera aplicada a los resultados de una política pública (regresividad de resultados), entendiéndose que es regresiva cuando sus resultados empeoran en relación con los de un punto de partida temporalmente anterior elegido como parámetro. Y la segunda aplicada a la extensión de los derechos concedidos por una norma (regresividad normativa), determinándose que la norma es regresiva cuando al compararla con la norma que ha modificado o sustituido, la norma posterior suprime, limita o restringe derechos o beneficios concedidos por la anterior, de tal manera que "el estándar de juicio de regresividad normativa consiste en evaluar si el nivel de protección que ofrece el ordenamiento 
jurídico ante una misma situación de hecho ha empeorado" (p. 6).

Según Courtis (p. 5), el "nivel de satisfacción de las aspiraciones de los diversos sectores de la sociedad" al que alude el artículo 5.2. de las "Normas para la confección de los informes periódicos previstos en el artículo 19 del Protocolo de San Salvador", corresponde al "ámbito en el que pueden emplearse indicadores o referentes empíricos referidos al nivel de satisfacción de derechos tales como el acceso a servicios de salud, el acceso a servicios educativos, el acceso a la alimentación, el acceso a vivienda, etcétera, y la calidad de esos servicios o políticas en términos de resultados, ...". El parágrafo del mismo artículo reconoce una dimensión normativa al identificar la recepción constitucional, el desarrollo legal e institucional y las prácticas de gobierno de los Estados, como aspectos que reflejan el cumplimiento de la obligación de progresividad (p. 6).

Son regresivas entonces, las disposiciones normativas que impliquen un retroceso en la extensión concedida a un derecho y las políticas que impliquen un retroceso en los resultados, medibles a través de indicadores o referentes empíricos (p. 6).

En cuanto a las nociones de regresividad frente a la exigibilidad judicial de los derechos sociales, Courtis considera que "el estándar de juicio de regresividad normativa consiste en evaluar si el nivel de protección que ofrece el ordenamiento jurídico ante una misma situación de hecho ha empeorado" (p. 6). Y en lo que corresponde a la aplicación judicial de la noción de regresividad de resultados resulta más difícil, puesto que los tribunales están acostumbrados a juzgar sobre problemas litigiosos muy delimitados, y proponerles la discusión de una serie de variables relacionadas con la política pública da lugar al rechazo de la cuestión por falta de competencia técnica o política (p. 7), pareciendo más adecuados "los mecanismos de seguimiento periódico de las políticas públicas, tales como los ofrecidos por los mecanismos de informes previstos por los tratados de derechos humanos del sistema universal, $u$ otros similares a nivel local, como las evaluaciones periódicas de instituciones nacionales de defensa y protección de los derechos humanos, u "observatorios" de organizaciones de la sociedad civil" (p. 8).

Con respecto a la obligación estatal de implementación progresiva de los derechos económicos, sociales y culturales surgida del artículo 11.1. del PIDESC, Courtis extrae algunas obligaciones concretas a cargo del Estado. Por un lado la obligación de no regresividad consistente en la prohibición de adoptar políticas y medidas, y de sancionar leyes que empeoren la situación de los derechos de los que gozaba la población al momento de adopción del tratado o en cada mejora progresiva; y por otro lado, la prohibición de reducir los niveles de protección de los derechos vigentes o derogar los ya existentes (pp. 9-10).

Courtis (p. 17) define la obligación de no regresividad como una limitación que los trata- 
dos de derechos humanos y la Constitución impone sobre los poderes Legislativo y Ejecutivo ( $\mathrm{sic}$ ) a las posibilidades de reglamentación de los derechos económicos, sociales y culturales. Fundamenta tal prohibición en primer lugar en la extensión de la seguridad jurídica y la protección de la confianza, nacidas en el Estado de derecho liberal, al campo de las normas y medidas adoptadas en el Estado Social de Derecho; y en segundo lugar con el contenido material del principio de Estado Social, referido a la satisfacción para todo ser humano de necesidades básicas, a la luz de la noción de dignidad humana y desarrollo material y científico de la sociedad, considerando de manera preferencial a aquellas personas que están en peor situación (pp. 18-19). La prohibición de regresividad opera como una cláusula de control jurídico de cumplimiento por parte de las autoridades del mandato de Estado Social (pp. 20-21).

Para efectos de establecer una metodología judicial de análisis de regresividad de una norma, Courtis (p. 29) señala que aquella corresponde a un control de razonabilidad de la reglamentación, limitación o restricción de un derecho social, agregando un elemento complementario, por lo que la obligación de no regresividad implica un control "agravado". Efectivamente el legislador y el Ejecutivo, dentro de la concepción tradicional de razonabilidad, están sometidos a la no afectación de la sustancia del Derecho, el análisis de la relación medio/fin que propone la norma y el análisis de proporcionalidad. La obligación de regresividad agrega limitacio- nes vinculadas con la evolución histórica, ya que la reglamentación no puede empeorar el alcance y amplitud de goce del derecho vigente (p. 22). En este sentido el control de razonabilidad con la prohibición de regresividad en materia de derechos sociales, debe examinar que la norma no destruya el contenido esencial del derecho que reglamenta o lo reconozca más allá de los límites de su definición afectando otros derechos (p. 25), "que la restricción de los derechos se encuentre justificada por los hechos o circunstancias sociales que le han dado origen y por los fines lícitos perseguidos por la norma" (fl. 27) y "la determinación de la adecuada proporcionalidad entre las restricciones y los antecedentes y fines de la medida" (p. 28).

En la misma metodología judicial de control de regresividad, una vez se determina la regresividad de la norma, al acreditarse que el grado de protección ofrecido por la nueva norma constituye un retroceso con respecto al existente con la norma anterior, nace una presunción de invalidez de la nueva norma en la que se invierte la carga de la prueba y le corresponde al Estado demostrar la racionalidad de la norma, es decir, que a pesar de ser regresiva es justificable (pp. 29-33), en cuanto a la estricta necesidad de la medida por la existencia de un interés estatal calificado, el carácter imperioso de la medida y la inexistencia de alternativas menos restrictivas del Derecho (p. 37).

Courtis (pp. 39-40) refiere que el estándar de juicio para considerar justificada y permisible la medida es alto, quedando "excluidas 
de la posibilidad de ser justificadas las medidas regresivas que afecten el contenido mínimo esencial del derecho en juego", y el Estado solo puede justificar la adopción de las demás medidas regresivas cuando haya efectuado una cuidadosa evaluación de las alternativas, el objetivo perseguido por la medida sea el de proteger la totalidad de los derechos de PIDESC y la adopción de la medida haya tenido en consideración el máximo de los recursos disponibles.

Para el efecto se debe acudir a un juicio de razonabilidad en el que se exige al Estado la obligación absoluta de cumplimiento del contenido mínimo esencial del Derecho, y la demostración de un fin legítimo y razones estrictas para la justificación de la necesidad de la medida. Además se debe realizar el examen de proporcionalidad de la medida adoptada, donde resulta útil el empleo de un juicio de ponderación, donde se evalúa la proporcionalidad del sacrificio del derecho restringido, en comparación con la importancia del objetivo perseguido. "En caso de duda, habrá de estarse contra la validez de la norma regresiva" (pp. 40-41).

Courtis (pp. 41-42) explica que el principio de interpretación in dubio pro iusticia socialis favorece la vigencia de la norma de Derecho Social de mayor alcance y "en el caso de la prohibición de regresividad, se somete a escrutinio estricto a la norma posterior que pretende limitar la extensión del Derecho". Una norma que reglamenta o implementa un derecho social es regresiva con respecto a otra, cuando limita, restringe o reduce la extensión o el sentido de un derecho social, o le impone a su ejercicio condiciones que con anterioridad no debían sortearse, es decir, cuando es menos favorable para el titular del Derecho.

Por otro lado, Nikken (2010, p. 71) refiere que la progresividad es una de las características de los Derechos Humanos, al explicar que como estos "son inherentes a la persona y su existencia no depende del reconocimiento de un Estado, siempre es posible extender el ámbito de la protección a derechos que anteriormente no gozaban de la misma. Ha sido así como se ha ensanchado sucesivamente el ámbito de los derechos humanos y su protección, tanto a nivel doméstico como en la esfera internacional".

En el caso colombiano, se tiene que el artículo 94 de la Constitución Política de 1991, consagra que "la enunciación de los derechos y garantías contenidos en la Constitución y en los convenios internacionales vigentes, no debe entenderse como negación de otros que, siendo inherentes a la persona humana, no figuren expresamente en ellos".

Con respecto a la exigibilidad de los derechos humanos frente a la característica de progresividad, Nikken (p. 73) explica que:

La progresividad no debe entenderse como una nota de la exigibilidad de los derechos humanos, en el sentido de que esta nos sería inmediatamente realizable. Por el contrario, una vez identificado un derecho determinado 
como "inherente a la dignidad de la persona humana", este merece protección inmediata como tal. La progresividad, como aquí la entendemos, lo que denota es que la "aparición", es decir, el reconocimiento de los derechos humanos se ha ampliado progresivamente y que esa ampliación es irreversible. Asimismo, que el número y el vigor de los medios de protección también ha crecido de manera progresiva e igualmente irreversible, porque en materia de derechos humanos, toda regresividad es ilegítima.

Nikken (p. 87) también establece la progresividad como una característica del Derecho Internacional de los Derechos Humanos, al señalar que en el desarrollo de su protección se "demuestra la existencia de una tendencia manifiesta hacia la extensión de su ámbito de modo continuado e irreversible, tanto en lo tocante al número y contenido de los derechos protegidos como en lo que se refiere a la eficacia y el vigor de las instituciones internacionales de protección".

Para el efecto se explica que los derechos civiles y políticos no fueron objeto de reconocimiento universal desde su aparición. Así mismo el reconocimiento de los derechos económicos, sociales y culturales fue una conquista posterior a la de los derechos civiles y políticos, cuando estaba aún pendiente la conquista de muchos de estos últimos. Por lo tanto, los derechos civiles y políticos no son ajenos a la progresividad atribuida a los derechos económicos, sociales y culturales (pp. 121-122).

En este sentido, Picard de Orsini y Useche (2005, p. 427) afirman que "los derechos humanos se encuentran en una constante evolución desde el momento en que surgió la Declaración Universal de Derechos Humanos en 1948 y, haciendo referencia al principio de progresividad, en cuanto que los preceptos que se refieren a cada derecho, han ido ampliándose en su contenido a través de los diversos tratados y convenciones que los contienen, desarrollando el ámbito del Derecho y sus garantías;...".

Muñoz Segura (2010, p. 99) señala que el principio de progresividad es una de las limitantes constitucionales con las que cuenta el desarrollo legislativo de los derechos sociales, económicos y culturales, y "que inició como un postulado mucho más abstracto, como un propósito, para convertirse cada vez más en un elemento cierto y exigible judicialmente dentro del sistema pensional colombiano", siendo posible debatir ante la justicia constitucional si los cambios legislativos son compatibles con dicho principio y "exigir la aplicación del principio de progresividad y no regresividad en casos concretos" (p. 107).

\section{Otras acepciones jurídicas del principio de} progresividad. También debe indicarse que en material procesal penal el principio de progresividad hace referencia, como objeto del control de legalidad, a la relación, dentro del contexto del proceso penal, de una 
serie de pasos en el conocimiento que llevan desde la incertidumbre inicial de la denuncia o conocimiento de la notitia criminis, hasta la certeza que como factor necesario se demanda en el fallo condenatorio (Corte Suprema de Justicia. Sala de Casación Penal. M. P. Dr. Sigifredo Espinosa Pérez. Proceso No. 30164)*. Según el principio de progresividad, la actividad que se cumple en cada una de las etapas que componen el proceso penal "se adelanta con la finalidad de alcanzar mayores grados en el conocimiento del objeto de la investigación, pasando de la incertidumbre, a la certeza de lo realmente acaecido" (Corte Suprema de Justicia. Sala de Casación Penal. M. P. Dr. Fernando Enrique Arboleda Ripoll. Proceso No. 15610$)^{\circ}$. En otras palabras (Corte Suprema de Justicia. Sala de Casación Penal. M. P. María del Rosario González de Lemos. Proceso No. 31052)", "el proceso penal se rige por el principio de progresividad cuya característica fundamental es que se avanza de un grado de ignorancia (ausencia de conocimiento) hasta llegar al de certeza, pasando por la probabilidad..." Es de advertir que esta acepción propia del Derecho Procesal Penal no es objeto de estudio en este texto.

En materia de Derecho Tributario, el principio de progresividad establecido en el artículo 363 de la Constitución Política, ha sido concebido por la jurisprudencia contenciosa

* Procesado: Gabriel Ernesto Arango Bacci. Aprobado Acta No. 206. Bogotá, D.C., veintiocho (28) de julio de dos mil ocho (2008).

- Procesado: Lucas Gnecco Cerchar. Sentencia Única Instancia, Santafé de Bogotá, 26 de octubre de 2010.

\& Aprobado Acta No. 138. Bogotá D.C., mayo trece (13) de dos mil nueve (2009). administrativa (Consejo de Estado. Sala de lo Contencioso Administrativo. Sección Cuarta)- como aquel que se asocia al reparto de la carga tributaria entre los diferentes obligados a su pago, según la capacidad contributiva de la que disponen, de modo que el sistema que conserva las diferencias entre los aportantes de mayor y menor capacidad contributiva, es neutro; el que las reduce es progresivo; y el que las aumenta es regresivo. De tal manera que la carga tributaria sea mayor cuando mayores sean los ingresos y el patrimonio del contribuyente (Consejo de Estado. Sala de lo Contencioso Administrativo. Sección Cuarta) ${ }^{\triangleright}$. El principio de progresividad se refiere a la distribución de las cargas que impone el sistema tributario y los beneficios que este genera, además mide cómo una carga o un beneficio tributario modifica la situación económica de un grupo de personas en comparación con los demás.

La Corte Constitucional en Sentencia C-419 de 1995 indicó que el principio de progresividad en materia de Derecho Tributario se deduce del principio de equidad vertical,

- Consejera Ponente (E): Martha Teresa Briceño de Valencia. Bogotá D. C., cuatro (04) de febrero del dos mil diez (2010). Radicación número: 25000-23-27-000-200301655-02(16634). Actor: Roberto Uribe Pinto. Demandado: Municipio de Anapoima; y Consejo de Estado. Sala de lo Contencioso Administrativo. Sección Cuarta. Consejera ponente: Carmen Teresa Ortiz de Rodríguez. Bogotá, D. C. primero $\left(1^{\circ}\right)$ de marzo de dos mil doce (2012). Radicación número: 25000-23-27-000-200200599-01(18256). Actor: Empresa de Energía de Bogotá S.A. E.S.P. Demandado: Municipio de El Colegio, Cundinamarca.

- Consejero ponente: William Giraldo Giraldo. Bogotá, D. C., agosto once (11) de dos mil once (2011). Radicación número: 25000-23-27-000-2007-00098-02(17556). Actor: Marcel Tangarife Torres. Demandado: Municipio de Chía. 
puesto que aquel "permite otorgar un tratamiento diferencial en relación con los contribuyentes de mayor renta, de manera que progresivamente terminan aportando más ingresos al Estado por la mayor tributación a que están obligados".

En Sentencia C-643 de 2002, se fijaron los alcances de la progresividad en los siguientes términos:

El principio de progresividad compensa la insuficiencia del principio de proporcionalidad en el sistema tributario pues como en este ámbito no basta con mantener en todos los niveles una relación simplemente porcentual entre la capacidad económica del contribuyente y el monto de los impuestos a su cargo, el constituyente ha superado esa deficiencia disponiendo que quienes tienen mayor patrimonio y perciben mayores ingresos aporten en mayor proporción al financiamiento de los gastos del Estado; es decir, se trata de que la carga tributaria sea mayor entre mayores sean los ingresos y el patrimonio del contribuyente.

También se aclara que la anterior concepción propia del Derecho Tributario tampoco es objeto de profundización en este trabajo.

En el Estado constitucional, social, democrático y ambiental de Derecho. Es indudable que la Constitución Política de Colombia de 1991 ha venido trayendo grandes cambios en la vida política de la sociedad colombiana. Uno de esos cambios se ha referido a la introducción y divulgación de diferentes instituciones políticas y jurídicas que antes de 1991 eran ajenas al conocimiento y apropiación de la mayoría de los colombianos y colombianas.

El Estado constitucional, social, democrático y ambiental de Derecho, como concepción del Estado colombiano, es una de las innovaciones que ha cobrado gran fuerza jurídica y desarrollo político en los últimos años. La actividad del Estado colombiano, en el ejercicio de sus diferentes funciones, ya sea legislativa, ejecutiva, judicial, fiscalizadora, electoral o constituyente, se ha visto influenciada por el contenido del Estado constitucional, social, democrático y ambiental de Derecho. Pero, desde una finalidad pedagógica, ¿qué significa esta nueva concepción del Estado colombiano?

Con este propósito se hace necesario comentar varios términos: Estado, Estado constitucional, Estado social, Estado democrático, Estado ambiental y Estado de Derecho.

En primer lugar, remitiéndonos al exmagistrado de la Corte Constitucional Vladimiro Naranjo Mesa (2000, pp. 86-87), el Estado se define como "un conglomerado social, política y jurídicamente constituido, asentado sobre un territorio determinado, sometido a una autoridad ejercida por sus propios órganos y cuya soberanía es reconocida por otros Estados". Esta definición hace revaluar la restringida idea que se tiene sobre Estado, al considerarlo simplemente como el conjunto de personas e instituciones que ejercen el 
poder político. En realidad debe interpretarse que el Estado tiene una conformación integral así: Un elemento humano referido a la población, un elemento físico representado por el territorio, un elemento jurídico-político evidenciado en el poder político ejercido por las autoridades y finalmente, un elemento declarativo dado por el reconocimiento internacional de su soberanía.

En segundo lugar, el Estado constitucional se refiere a que todo lo atinente a los derechos y libertades de las personas y la organización, estructura y funcionamiento del Estado se encuentra regulado dentro del marco de una Constitución. Es decir, que la Constitución Política regula lo relacionado, por un lado, con los catálogos de derechos y sus mecanismos de protección, y por otro lado, con los habitantes (nacionalidad, ciudadanía y extranjeros), el territorio (límites, conformación y régimen jurídico) y el ejercicio del poder público por parte de los gobernantes (titularidad, designación, competencia y controles).

En tercer lugar, tenemos que el Estado Social implica una actividad permanente del aparato estatal en garantizar a todas las personas condiciones de vida dignas, de tal manera que su dinámica permita superar las desigualdades que se presentan en la sociedad y promover la igualdad de oportunidades para todas y todos, buscando que en la práctica la igualdad sea real y efectiva.

En cuarto lugar, la concepción de Estado que consagra la Constitución Política de 1991 ha- bla de un Estado democrático que se caracteriza por dos aspectos fundamentalmente: El derecho que tienen los ciudadanas y ciudadanos de participar en la conformación y ejercicio del poder político, a través de la elección periódica de los gobernantes, y la facultad de participar en la toma de decisiones, por medio de los mecanismos de participación ciudadana, que han permitido hablar de la democracia participativa.

En quinto lugar, se observa que entre los adjetivos que califican al Estado colombiano se encuentra la novedad del rótulo de ambiental. Podríamos definir en términos generales y a partir del contenido constitucional, que el Estado ambiental hace referencia a que las autoridades y las personas están obligadas a proteger el ambiente y garantizar su sostenibilidad, al igual que el gozar de un ambiente sano es un derecho de toda persona. En palabras de la Corte Constitucional en Sentencia C-126 de 1998, "Ia protección al medioambiente es un principio que irradia todo el orden jurídico puesto que es obligación del Estado proteger las riquezas naturales de la Nación".

En lo que respecta a la importancia de lo ambiental en el marco de la Constitución Política de 1991, son varios de sus artículos los que mencionan la protección ambiental. Dada la situación anterior, la jurisprudencia de la Corte Constitucional en la Sentencia T-411 de 1992 (Magistrado Ponente: Alejandro Martínez Caballero) acuñó el concepto de Constitución Ecológica, conformada por 34 disposiciones que regulan la relación de 
la sociedad con la naturaleza y que buscan proteger el medioambiente. Vale la pena mencionar, entre dichas normas, los artículos 8 o sobre la obligación de proteger las riquezas culturales y naturales de la Nación, 58 que establece la función ecológica de la propiedad, 79 que consagra el goce de un ambiente sano como un derecho colectivo y 95, numeral 8, que relaciona como deber de toda persona velar por la conservación de un ambiente sano.

En sexto lugar, el Estado de Derecho data de la visión liberal promovida por el pensamiento político y filosófico que influenció la Revolución Francesa. El Estado de Derecho establece la limitación del poder político ejercido por los gobernantes, el que debe estar sometido al ordenamiento jurídico en aras de proteger los derechos y libertades de las personas.

De todo lo anterior, se colige entonces que la definición del Estado colombiano es muy precisa y compleja, por cuanto se refiere a aquella visión de Nación identificada por valores, entendida como un grupo de personas, dentro de un territorio, que tiene unos gobernantes elegidos democráticamente y sometidos al ordenamiento jurídico, que participa activamente en la toma de decisiones, que vela por la conservación y sostenibilidad ambiental, cuya soberanía es reconocida internacionalmente y que promueve la igualdad real y efectiva para todos sus integrantes, dentro del marco de una Constitución Política.
Este panorama ha obligado a replantear el objeto de estudio del Derecho en Colombia. Efectivamente, se señala que el Derecho tiene por objeto todo el universo jurídico, incluyendo la ley en sentido general, los principios generales del Derecho y la jurisprudencia, o que su campo de acción solo se circunscribe a la norma jurídica como texto escrito. Pero en las ciencias jurídicas ya no encontramos objetos de investigación, y especialmente cuando el cometido es la realización de un Estado constitucional, social, democrático y ambiental de Derecho, donde se presentan escenarios plurales que desarrollan multitud de relaciones sociales. En este sentido, el interés del Derecho no se limita a lo normativo, ya que ahora su objeto recae sobre las relaciones, redes y problemas jurídicos, políticos, económicos, culturales y ambientales que se suceden en el contexto de una sociedad pluralista que pretende teóricamente la realización de los cometidos constitucionales y que en la práctica toma decisiones públicas que ponderan los diferentes intereses en juego.

El principio de progresividad y no regresividad se constituye en un límite a las normas y medidas públicas, en el sentido que no pueden disminuir el nivel de protección alcanzado ni crear obstáculos para lograr los cometidos de un Estado constitucional, social, democrático y ambiental de Derecho, impidiendo "promover la prosperidad general y garantizar la efectividad de los principios, derechos y deberes consagrados en la Constitución; facilitar la participación de todos en las decisiones que los afectan y en 
la vida económica, política, administrativa y cultural de la Nación", fines esenciales del Estado según lo consagrado en el artículo 2으 de la Constitución Política de Colombia de 1991. Es decir, que el modelo de Estado adoptado en Colombia debe garantizar la efectividad progresiva y no regresiva de los derechos constitucionales.

\section{CONCLUSIONES}

Del análisis realizado, a título de conclusiones, se puede indicar que las normas son reglas o principios. Mientras los principios son mandatos de optimización que pueden ser cumplidos en diversos grados que dependen de las posibilidades fácticas y jurídicas, las reglas son normas que solo pueden ser cumplidas o incumplidas. Los principios constituyen una pauta de interpretación jurídica válida e importante en la aplicación de los derechos, incluyendo los sociales, económicos y culturales.

El principio de progresividad tiene sustento en el Derecho Internacional de los Derechos Humanos, ya que este contempla la obligación de los Estados de lograr el desarrollo progresivo de los derechos económicos, sociales y culturales. La progresividad es una de las características de los derechos humanos.

Finalmente, debe señalarse que el principio de progresividad y no regresividad de los derechos, concebido como la obligación del Estado de adoptar medidas, hasta el máximo de los recursos disponibles, a fin de lograr la plena efectividad de la faceta prestacio- nal de los derechos constitucionales, es un elemento definitorio y estructural del modelo de Estado adoptado y, por tanto, dicho principio se constituye en referente para las autoridades públicas, en ejercicio de sus funciones, para el cometido de materialización del Estado constitucional, social, democrático y ambiental de Derecho consagrado en la Constitución Política de Colombia de 1991.

\section{REFERENCIAS BIBLIOGRÁFICAS}

Alexy, R. (1993). Teoría de los derechos fundamentales. Madrid: Centro de Estudios Constitucionales.

Atienza, M. \& Ruiz Manero, J. (1991). Sobre principios y reglas. Doxa, 10, 101-120.

Calvo Chaves, N. J. (2011). Aplicación del principio de progresividad en la jurisprudencia constitucional colombiana. Memorando de Derecho, 02, 63-81.

Comité del Pacto de Derechos Económicos, Sociales y Culturales (1990). Observación General 3. La índole de las obligaciones de los Estados Partes (Artículo 11 [2] del Pacto Internacional de Derechos Económicos, Sociales y Culturales). Recuperado el 1 o de noviembre de 2012, de http://www2.fices. unsl.edu.ar/ prosoc/material/14bOG3.pdf observación general No. 3

Consejo de Estado (2012). Providencias 1992-2012 [en línea]. Recuperado hasta el 31 de octubre de 2012, de http://www.consejodeestado.gov.co/ 
Consejo de Estado. Sala de lo Contencioso Administrativo. Sección Cuarta. Consejera Ponente (E): Martha Teresa Briceño de Valencia. Bogotá D. C., cuatro (04) de febrero del dos mil diez (2010). Radicación número: 25000-23-27-000-2003-01655-02(16634). Actor: Roberto Uribe Pinto. Demandado: Municipio de Anapoima; y Consejo de Estado. Sala de lo Contencioso Administrativo. Sección Cuarta. Consejera ponente: Carmen Teresa Ortiz de Rodríguez. Bogotá, D. C. primero $\left(1^{\circ}\right)$ de marzo de dos mil doce (2012). Radicación número: 25000-23-27-000-200200599-01 (18256). Actor: Empresa de Energía de Bogotá S.A. E.S.P. Demandado: Municipio de El Colegio, Cundinamarca.

Consejo de Estado. Sala de lo Contencioso Administrativo. Sección Cuarta. Consejero ponente: William Giraldo Giraldo. Bogotá, D. C., agosto once (11) de dos mil once (2011). Radicación número: 25000-23-27-000-200700098-02(17556). Actor: Marcel Tangarife Torres. Demandado: Municipio de Chía.

Corte Constitucional Sentencia C-443 de 2009. Referencia: expediente D-7419. Demanda de inconstitucionalidad contra el artículo 34 (parcial) de la Ley 685 de 2001 "por la cual se expide el Código de Minas". Actores: Daniel Manrique y Jerónimo Rodríguez Lugo. M. P. Dr. Humberto Antonio Sierra Porto. Bogotá, D. C., ocho (8) de julio de dos mil nueve (2009).

Corte Constitucional. C-228 de 2011. Referencia: expediente D-8216. Demanda de inconstitucionalidad parcial del artículo $6^{\circ}$ del
Decreto-Ley 1282 de 1994 y parcial de los artículos 9 y 10 de la Ley 797 de 2003. Actores: María Fernanda Orozco Tous y Nixon Torres Cárcamo. M. P. Juan Carlos Henao Pérez. Bogotá, D.C., treinta (30) de marzo de dos mil once (2011).

Corte Constitucional. Sentencia C-272 de 2009. Referencia: expediente D-7670. Accionante: Hernán Antonio Barrero Bravo. Demanda de inconstitucionalidad contra el artículo 1 (parcial) de la Ley 860 de 2003. M. P. Dra. María Victoria Calle Correa. Bogotá, D. C., catorce (14) de octubre de dos mil nueve (2009).

Corte Suprema de Justicia. Sala de Casación Penal. M. P. Dr. Fernando Enrique Arboleda Ripoll. Proceso No. 15610. Procesado: Lucas Gnecco Cerchar. Sentencia Única Instancia, Santafé de Bogotá, 26 de octubre de 2010.

Corte Suprema de Justicia. Sala de Casación Penal. M. P. Dr. Sigifredo Espinosa Pérez. Proceso No. 30164. Procesado: Gabriel Ernesto Arango Bacci. Aprobado Acta No. 206. Bogotá, D. C., veintiocho (28) de julio de dos mil ocho (2008).

Corte Suprema de Justicia. Sala de Casación Penal. M. P. María del Rosario González de Lemos. Proceso No. 31052. Aprobado Acta No. 138. Bogotá D.C., mayo trece (13) de dos mil nueve (2009).

Corte Constitucional (2012). Relatoría [en línea]. Recuperado hasta el 31 de octubre de 2012, de http://www.constitucional.gov.co/ 
Courtis, C. (2006). La prohibición de regresividad en materia de derechos sociales: apuntes introductorios. En C. Courtis (Comp.), Ni un paso atrás: La prohibición de regresividad en materia de derechos sociales (pp. 3-52). Buenos Aires: Editores del Puerto.

Directrices de Maastricht sobre Violaciones a los Derechos Económicos, Sociales y Culturales (1997). Recuperado el 6 de noviembre de 2012, de http://ip.aaas.org/escrdocs_sp. nsf/287fccf1bc425ff4852567590054d44b/7 7e0aa4feb3691a18525691c0068932a?Open Document

Dworkin, R. (1984). Los derechos en serio. Barcelona: Ariel.

Muñoz Segura, A. M. (2010). El principio de progresividad en la jurisprudencia constitucional colombiana. Revista Latinoamericana de Derecho Social, 11, 93-109.

Naranjo Mesa, V. (2000). Teoría Constitucional e Instituciones Políticas. Bogotá: Temis.

Nikken, P. (2010). La protección de los Derechos Humanos: haciendo efectiva la progresividad de los derechos económicos, sociales y culturales. Recuperado el 10 de noviembre de 2012, de http://www.corteidh.or.cr/tablas/r25563.pdf.

Picard de Orsini, M. \& Useche, J. (2005). El principio de progresividad y la actuación de los órganos de Poder Público conforme a la Constitución vigente. Provincia, número especial, 421-449.

Principios de Limburgo sobre la Aplicación del Pacto Internacional de Derechos Económicos, Sociales y Culturales (1986). Recuperado el 6 de noviembre de 2012 de http:// www.pgjdf.gob.mx/temas/4-6-1/fuentes/3A-6.pdf

Uprimny, R. \& Guarnizo, D. (2006). ¿Es posible una dogmática adecuada sobre la prohibición de regresividad? Un enfoque desde la jurisprudencia constitucional colombiana. Recuperado el 1 o de noviembre de 2012, de http://www.dejusticia.org/index.php?modo=interna\&tema=derechos_ sociales \&publicacion $=180$ 
